\title{
The perspective of the Anthropology of music of Gannan xingguo Miao Huang
}

\author{
Jiangxi Science and Technology Normal University, NanChang 330013, China \\ peperiset@163.com
}

Keywords: TiaoXi, music view, GanNan.

\begin{abstract}
Tiao Xi ritual in XingGuo of GanNan areas is a ceremonial for blessing, disaster escaping, monster subduing, exorcism and home protecting, which has a certain influence in the southern region of JiangXi. This paper mainly explores the melody, rhythm and beat of XingGuo TiaoXi ritual from the point of music view, and the functional significance of XingGuo TiaoXi ritual music is also described here.
\end{abstract}

\section{Introduction}

In recent years, in the field of ethnomusicology, the research of ritual music has attracted more and more attention from researchers. XingGuo is located in southern of JingXi, northeast of GanNan. Tiao $\mathrm{Xi}$ is a Hakka traditional for blessing, disaster escaping, monster subduing, exorcism and home protecting, which hosting by two male masters[1-3]. TiaoXi is a folk activity with XingGuo characteristics, it combines elements from religious and folk music.

In the XingGuo TiaoXi ritual, music is an important means to implement each matters and accompanying in the entire ceremony. As sound effects and rhythmic effects beyond language, TiaoXi ritual music can connect ritual procedures, control ritual rhythm, render a good auditory environment by the special sound effect and create a sacred ritual space. it is a important constitute factor for ritual continuity and integrity.

For the vigorous development of ritual music research, base on the shape of region musical culture, this paper analysis and research the XingGuo TiaoXi ritual.

\section{Research of XingGuo Tiao Xi Ritual Music Shape}

The Category of TiaoXi Ritual Music. Vocal music is the main TiaoXi ritual music, which has many tracks. From the view of music using occasion, it can be divided into ceremony dedicate music and secular music. The ritual procedures and ritual music of TiaoXi are shown in the table 1.

Table 1 The ritual procedures and ritual music of TiaoXi

\begin{tabular}{|c|c|c|}
\hline Ritual procedures & Ritual music name & Ritual music shape \\
\hline Take stage and invite Gods & Zhuangshen & Ceremony dedicate music \\
\hline Greet guru & Greet guru & Ceremony dedicate music \\
\hline Sprinkle grain & Sprinkle grain song & Ceremony dedicate music \\
\hline Folk song of east river & Changmingfugui & Ceremony dedicate music \\
\hline Folk song of south river & Meilianlang & Secular music \\
\hline Shangwen biao & Zoubiao & Ceremony dedicate music \\
\hline Memorial general & Zhougao & Ceremony dedicate music \\
\hline Kill evil & Zhangsha & Ceremony dedicate music \\
\hline
\end{tabular}

After the procedure of kill evil, the ritual will extemporize different ceremony dedicate music for different circumstance, such as Zangjing will extemporize Tuan Hua, Tui Bing will extemporize Tui Bing and so an. And XingGuo folk song is alternate in the ritual.

The Vocal Music In TiaoXi Music. The TiaoXi ritual song has many froms. From the view of Cao Ben Ye, it can be divided into Shuobai, Yinyong, Nianchang, Yongchang and so on[4].

Shuobai is also called Nianbai. It is the vocal music form of jennifer holiday and near languages. Its style is most of prosiness or the different sentences and words of mixture of literary forms, and it is 
mainly for the Nian Wen Shu. Yinyong is used for reciting spells. Musical sound cavity melody is weaker. Nearly linguistic tones is along the framework of the pentatonic scale, a word a sound, in a relatively narrow range, and it has a certain rhythmic.

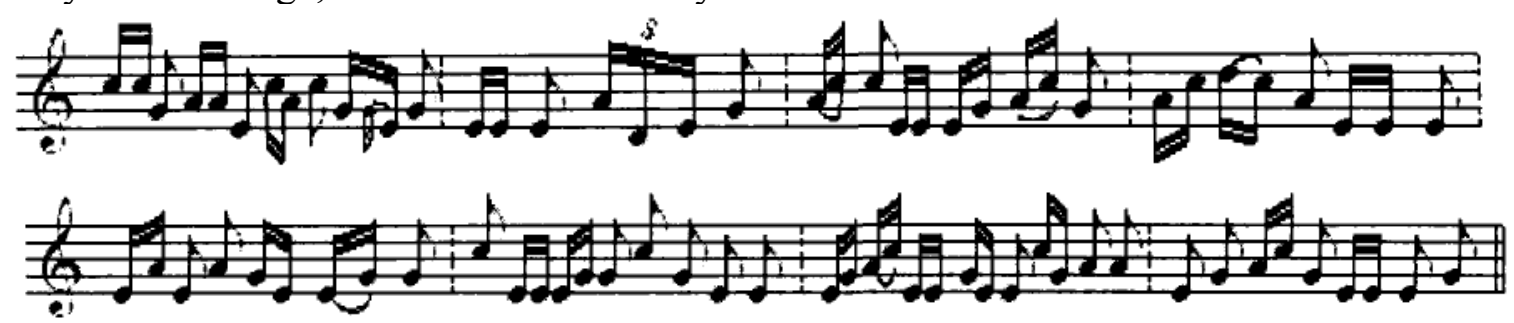

Fig 1 Shang Wen Biao

In the figure 1, the Shang Wen Biao is Yongchang, which has a strong melody sense. It is an important form of folk music and far languages. And it is an important music shape in TiaoXi ritual. It is also a main research object in this paper.

The Melody Characteristics of TiaoXi Song. The melody characteristics based on the core song cavity. The core song cavity is the cell and embryo of folk music. It Reflects the deep structural forms and inherent regularity of folk music, showing refined and general characteristics in structure. It is a core part of the musical structure in Concrete works and The highest rate of repeat melody tone row, which composite generally by about three sound. In the ritual, the melody of songs is based on sol, la, dol and do some defromation and displacement, thereby generating a distinctive melodic tone.
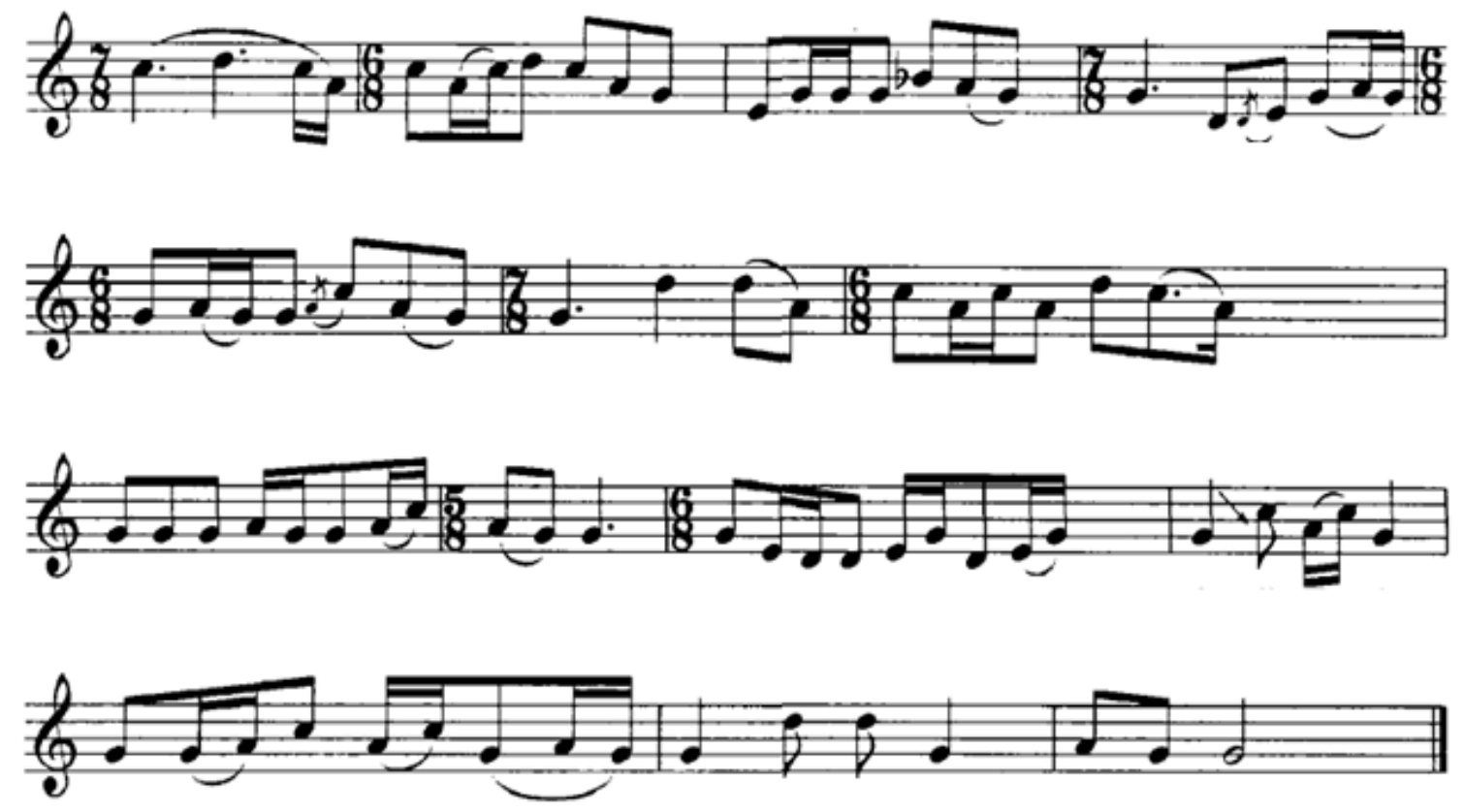

Fig 2 Take stage and invite Gods

Figure 2 is a typical example which based on sol, la, dol. Its modal scale is shown in figure 3 .

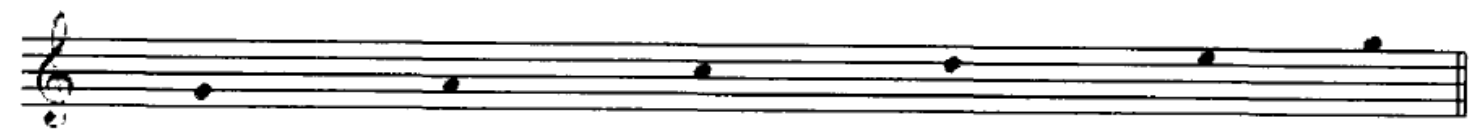

Fig 3 the modal scale of core song cavity

Palace tone has an important status in the melody, which is always in the downbeat. The main action of Shang tone appears between the two Palace tone. Angle tone does not appear alone, it is always connected with Shang tone and levy tone. 

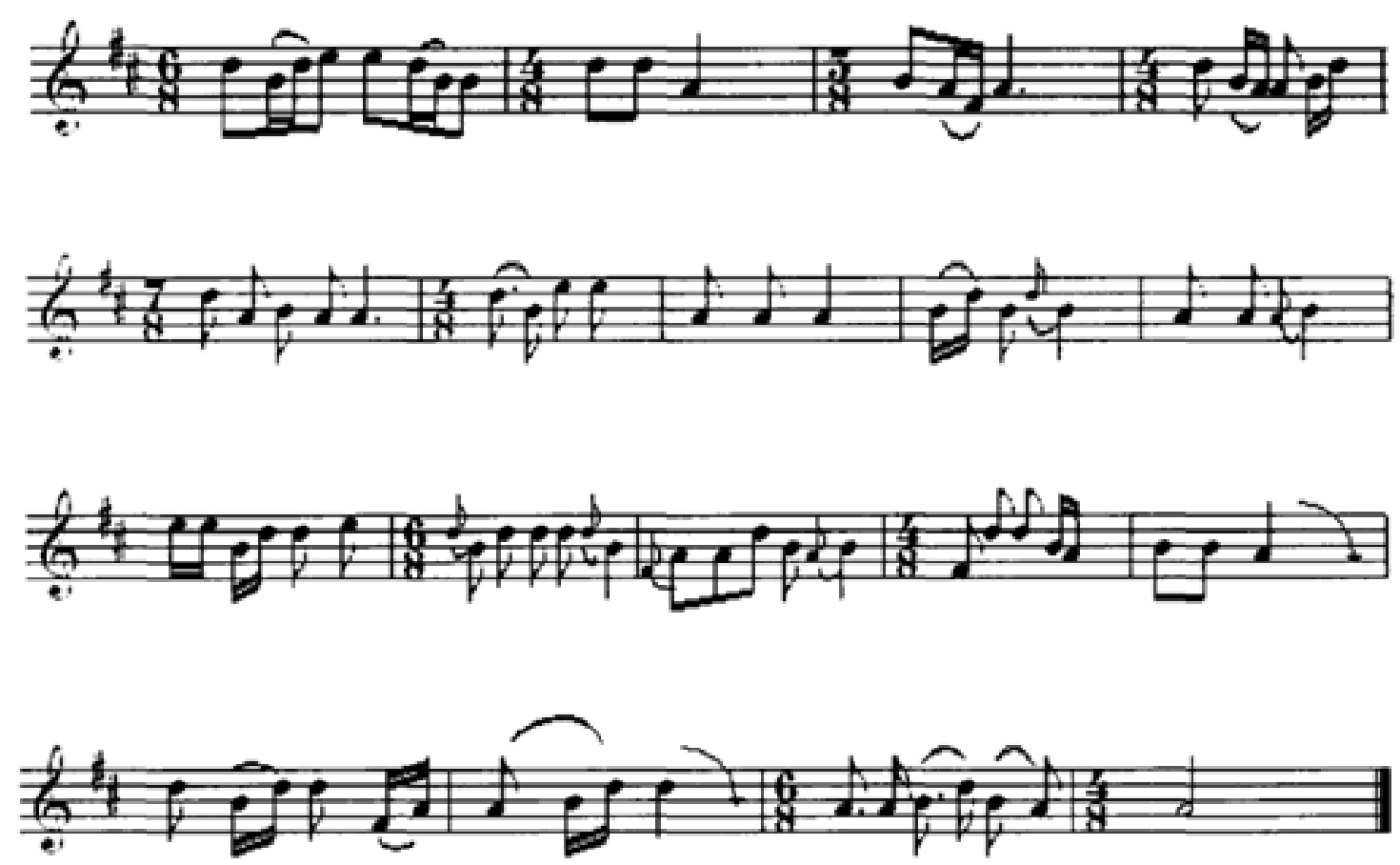

Fig 4 Worship Table

From the figure 2 and the figure 4, It is not difficult to find that they have a common rhyme chamber, that's, sol, la, do are all fine tune-up. Attack is the same with music-point, and The trend of melody is almost the same.

The Polyphonic Thinking in TiaoXi Song. TiaoXi is hosted by two masters, during the procedure, one master host the ritual and the other chimed sidelines. They are the complement for each other and alternately singing in most time, but which also has no lack of quartet parts.

For example, in figure 5, the last two sections of this fragment reflect as polyphonic shape, the zweistimmig melody of the third sections have a same starting point tone dol, then constitute three and four degrees respectively, the forth sections is Long tone. In figure 6 , the high vocal part of the third section has a eight beats long tone sustained, and the low vocal part do Free action, then they are made a comparison between the two vocal parts.

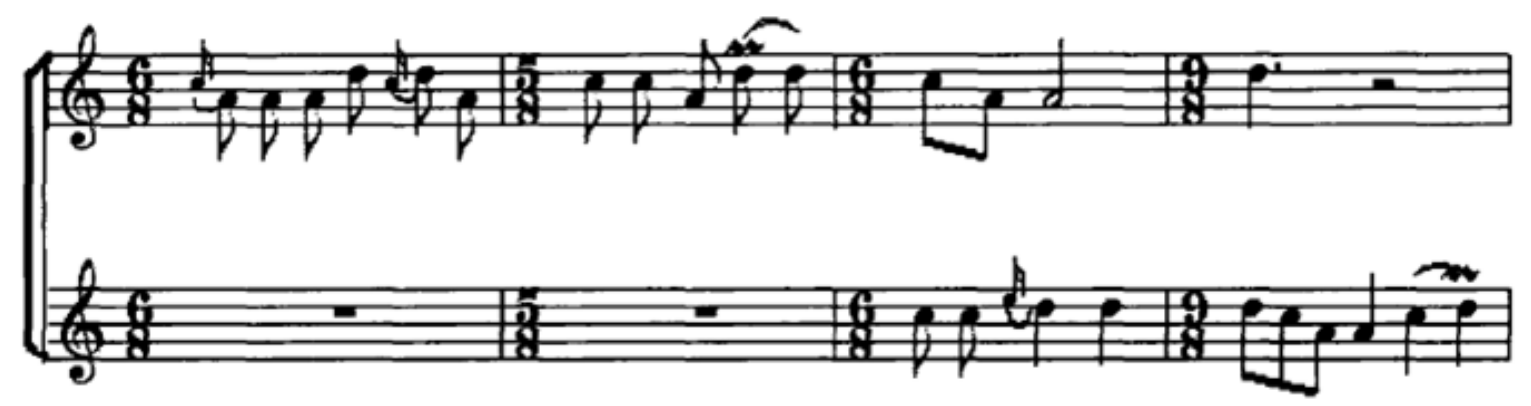

Fig 5 Ying Shi

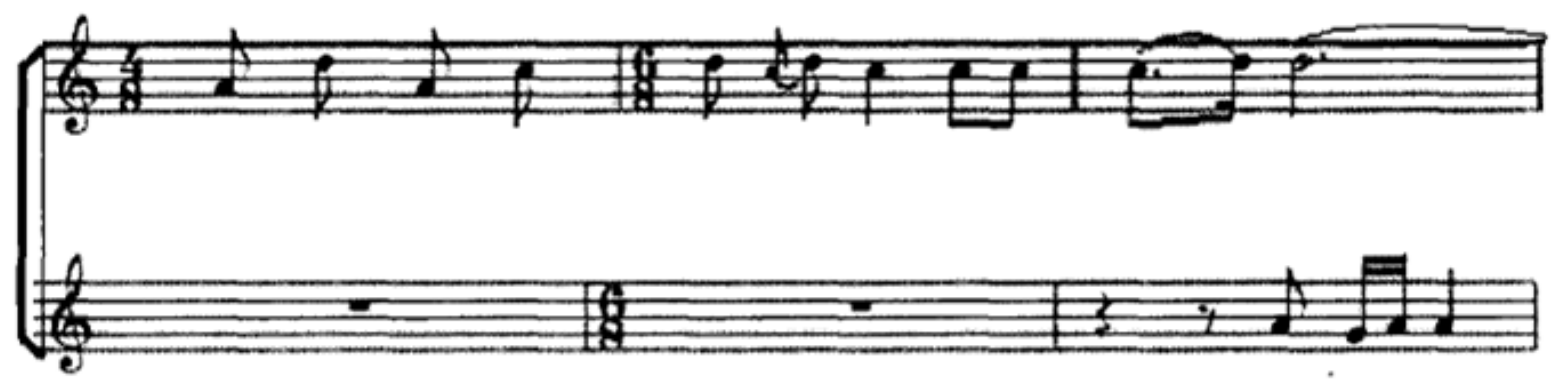

Fig 6 Ying Shi 


\section{The Functional Significance of XingGuo Tiao Xi Ritual Music}

Sacrifice and Pleasing Gods. The most important mean of music in sacrifice ritual is sacrifice and pleasing Gods. This utilitarian role widely present in a variety of rain god, Apollo and totem ritual ceremony from ancient times. People thought music can help Gods to control natural, since the characteristics of music, people can use it to engage in dialogue with Gods, coordination between human and Gods and adjust the contradiction between man and nature.

Aesthetic and Entertainment. Music in ceremony is not just to please the gods, they are also a way for participants to self-entertainment. As a set of religious and secular music, the secular tendency of TiaoXi becomes strongly in constant evolution, which makes it has more gradually prominent functional significance in Aesthetic and entertainment.

Ideological Purification. Music can make people have broad-minded and ideological purification. TiaoXi masters always extemporize different content folk songs based on different objects, Which includes such things as loyalty and filial piety and interpersonal ethics. It can make the viewer be educated in the subtle and ideological purification.

Inheritance Traditional XingGuo Folk Song. Like all folk songs, the mainly way to inheritance XingGuo folk song is based on oral tradition, inheritance the songs from generation to generation in daily life. In addition, there is a special inheritance way for XingGuo folk song, that's, TiaoXi ritual. It plays a particularly important role for the inheritance of XingGuo folk song.

\section{Conclusion}

Through the research on Tiao Xi ritual song and instrumental music, this paper found that the whole ceremony music reflected revolving structure morphology. In the ritual, the melody of songs is based on sol, la, do and do some defromation and displacement, thereby generating a distinctive melodic tone.

\section{Acknowledgements}

Cultural anthropology study of the Gannan xingguo tiaoxi ritual and its music,12YS02.

\section{References}

[1] Merria: The Anthropology of Music(Northwest University Press, 1964).

[2] Z.L. Song: The Original Birth Belief - On the Totem Worship and Shizu Chong, Vol. 32 (1983) No.13, p.21-24. (In Chinese)

[3] Y.B. Xue: Sacred Entertainment - Ethnographic Study of Chinese Folk Ritual and Music(Religious Culture Publishing House, 2003). (In Chinese)

[4] Benye Cao: Theoretical Orientation and Method of Ritual Music Study(Beijing: People's Music Publishing House, 2002). (In Chinese) 